\title{
Dry Sliding Wear Behaviour of As-Cast AZ31B Magnesium Alloy
}

\author{
Faruk MERT \\ Gazi University Faculty of Technology Department of Manufacturing Engineering, TR-06500 Ankara, Turkey, \\ E-mail: farukmert@gazi.edu.tr \\ Magnum Engineering R\&D Company, Gazi Teknopark, TR-06830 Ankara, Turkey, E-mail: faruk@magnumeng.com \\ cross $^{\text {ref }}$ http://dx.doi.org/10.5755/j01.mech.23.5.15761
}

\section{Introduction}

The specific strength of magnesium alloys provides engineers with an opportunity to change the traditional materials such as steel, cast iron or aluminium used in the transportation industry with these light-weight substitutes [1]. Good cast ability, considerable vibration and shock absorption ability, better machinability and high recycling potential are also the other advantages of magnesium alloys [2]. However, poor resistance to wear of magnesium alloys causes important limitations to extend their applications [3]. Nevertheless, data on friction and wear behaviour of magnesium alloys is quite insufficient although wear is a serious problem when magnesium alloys are subjected to sliding motion $[4,5]$. Normally, magnesium alloys are not appropriate material for sliding situations in which their surfaces could come into contact with other materials [6]. However, friction and wear must be considered due to heat generation when material processing by some methods such as rolling, extrusion, forging etc. [7, 8]. Therefore, the wear behaviour of magnesium alloys must be comprehensively investigated.

Wear behaviour investigation of magnesium alloys in the literature is quite limited. AZ91D magnesium alloy has been the most commonly used and the most investigated in terms of wear behaviour until now. The AZ91D magnesium alloy shows higher wear resistance than AS21 and AM60B alloys under similar material combinations [9-12]. An et al. [13] studied the friction and wear properties of ascast Mg-1Zn-2Y and Mg-9Al-1Zn magnesium alloys under dry sliding conditions using pin-on disc configuration. The results exhibited that $\mathrm{Mg}-1 \mathrm{Zn}-2 \mathrm{Y}$ has good wear resistance compared with AZ91 for applied loads excess of $80 \mathrm{~N}$. Chen et al. [14] studied the friction properties and wear behaviour of thixoformed and permanent mold cast AZ91 magnesium alloy under reciprocating sliding conditions using ball-on disk configuration. They revealed that wear resistance of thixoformed AZ91 alloy was notably better than permanent mold cast AZ91 alloy due to finer microstructure. Selvan and Ramanathan [15] investigated wear behaviour of as-cast ZE41A magnesium alloy against EN32 steel with 65 RC hardness as counter face using pin-on disc test apparatus. The results showed that sliding wear behaviour could be classified as three main wear regimes: mild wear, severe wear and ultra-severe wear regime, depending on the applied load and sliding velocity. In addition, Lopez et al. [16] investigated ZE41A magnesium alloy with T5 heat treated using pin-on disc test apparatus. Compared to Selvan and Ramanathan's [15] study, ZE41A magnesium alloy with T5 heat treated showed better wear resistance than without T5 condition. Taltavull et al. [17] studied the wear behaviour of AM60B magnesium alloy under dry sliding conditions using pin-on disc type test apparatus. They revealed that the wear rate increases with increasing in applied load and sliding velocity. Habibnejad-Korayem et al. [18] investigated the wear behaviour of pure magnesium, AZ31 magnesium alloy and their composites reinforced with 2 wt.\% $\mathrm{Al}_{2} \mathrm{O}_{3}$ nano-particles using pin-on disc test setup. The results indicated that the composites showed better wear resistance than pure magnesium and its alloys because of grain refinement, higher hardness and load bearing capacity. Ding et al. [19] investigated the wear properties of AZ31 magnesium alloy and its composites with $\mathrm{SiC}$ particles. They also revealed that the microhardness and wear resistance of composites were superior to that of as-received AZ31 magnesium alloy. In brief, the studies cited show that mild, severe and ultrasevere wear regimes were found and wear mechanisms such as abrasion, adhesion, oxidation, delamination, thermal softening, melting, plastic deformation, severe plastic deformation were observed for different wear conditions.

Although AZ31B magnesium alloy has good potential in lightweight applications, little effort has been made to study on the wear behaviour. This study investigates dry sliding wear behaviour of as-cast AZ31B magnesium alloy using a pin-on-disc type wear apparatus against an EN42 steel with heat treatment as counter face. A wear mapping approach has been undertaken to represent the wear regimes and the main mechanism of wear in each regime.

\section{Testing procedures}

A commercial as-cast AZ31B magnesium alloy (Mg-3\%Al-1\%Zn) used in this study were supplied by Xi'an Yuechen Metal Products Co., Ltd, China. The chemical composition of the studied alloy is given in Table 1. The cast material was supplied as round in $70 \mathrm{~mm}$ diameter and 300 mm length.

Table 1

Chemical composition and mechanical properties of investigated alloy (wt.\%)

\begin{tabular}{|c|c|c|c|c|c|c|}
\hline Alloy & $\mathrm{Mg}$ & $\mathrm{Al}$ & $\mathrm{Zn}$ & $\mathrm{Fe}$ & $\mathrm{Ni}$ & $\mathrm{Cu}$ \\
\hline AZ31B & Bal. & 3.12 & 1.05 & $<0.0017$ & $<0.0009$ & $<0.0007$ \\
\hline
\end{tabular}


The microstructure of the as-received alloy and the pin worn surfaces were examined by Scanning Electron Microscopy (SEM) (JEOL JSM-6060 LW) equipped with an Energy Dispersive X-ray Spectrometer (EDS). The metallographic samples were cut using a fine saw without heating and mounted in hardened epoxy resin. Then, the samples ground on emery paper up to 2000 grade and polished with diamond paste of $3 \mu \mathrm{m}$ particle size. The polished surfaces were cleaned ultrasonically in a methanol solution before etching. AZ31B specimens were etched using a mixture of acetic acid $(7 \mathrm{~mL})$, picric acid $(25 \mathrm{~g})$, ethanol $(140 \mathrm{~mL})$, and purified water $(40 \mathrm{~mL})$ for $20 \mathrm{~s}$ to reveal the microstructure.

The wear tests were accomplished under dry sliding condition in accordance with the ASTM G99-95a [20] standard using a pin-on disc wear testing machine. The pins of AZ31B magnesium alloy under investigation were machined to $6 \mathrm{~mm}$ in diameter and $10 \mathrm{~mm}$ in length. The surface preparation procedure of the wear test samples consisted of grinding surfaces manually up to 1200 grit $\mathrm{SiC}$ emery papers. The surfaces of the specimen were cleaned with acetone to avoid the presence of humidity and non-desirable deposits, dried by warm air. The counterface was EN42 steel disc (in HRC 55 hardness) of $150 \mathrm{~mm}$ in diameter and 18 $\mathrm{mm}$ in width having $R a=0.2 \mu \mathrm{m}$ surface roughness on which the test specimen slide. The steel disc was cleaned in an ethanol solution before each wear test.

The wear tests were performed using sliding velocities of $0.25,0.5,1$ and $2 \mathrm{~m} / \mathrm{s}$ and loads of 10, 20, 40 and 80 $\mathrm{N}$ with a constant sliding distance of $2500 \mathrm{~m}$. The mass losses were calculated from the differences in weight of specimens measured before and after the sliding test (after removing any loose debris) using a precision balance $(0.1$ $\mathrm{mg}$ ). Each test was repeated three times in order to check the reproducibility, and the average of the three tests was considered to determine the wear rate. Because the hardness of the steel disc face was far higher than the specimens and its wear volume was too small, the wear properties of the steel disc are not included in the analyses in the present study.

The volume lost during the wear test was determined from the mass lost using the alloy density to determine the wear rate. To evaluate the wear response of the material under different conditions, the Archard's law was applied [21]:

$$
\left(\frac{V}{L}\right)=K\left(\frac{W}{H}\right)=k W,
$$

where $V$ is the wear volume, $L$ is the sliding distance, being the coefficient $V / L$ the wear rate, $W$ is the applied load, $H$ is the hardness of the sample, $K$ is the Archard's constant and $k$ is the specific wear rate. Hardness measurements of the pins were measured using an EMCO TEST Duravision 200 machine with a $10 \mathrm{~N}$ load using ISO 6507-1standard [22]. Each hardness value was the average of the three test results.

\section{Results and discussion}

\subsection{Microstructure characterization}

The microstructure of as-cast AZ31B magnesium alloy was observed by SEM (Fig. 1). The alloy microstructure mainly includes $\alpha-\mathrm{Mg}$ phase as matrix and $\beta-\mathrm{Mg}_{17} \mathrm{Al}_{12}$ along the grain boundaries as second phase precipitate. The grain size is heterogeneously distributed in microstructure and measured as approximately $55 \mu \mathrm{m}$.

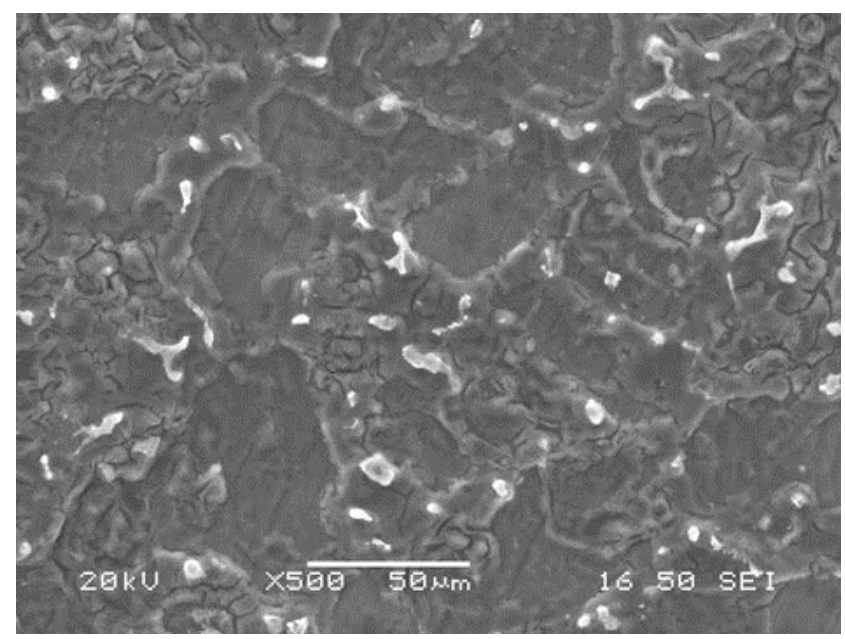

Fig. 1 Microstructure observation of as-cast AZ31B magnesium alloy

\subsection{Wear behaviour}

The volumetric wear rate of as-cast AZ31B magnesium alloy is represented versus applied loads for the tests controlled at a constant sliding speed of $0.25,0.5,1.0$ and $2.0 \mathrm{~m} / \mathrm{s}$ in Fig. 2. The wear rate is enhanced with increasing the applied load at whole sliding speeds. A great difference in wear rates was obtained at $20 \mathrm{~N}$ for as-cast alloy. The slope changes concurred with the transition from mild wear regime to severe wear regime [10]. These results show that mild wear is kept up to $20 \mathrm{~N}$ for the investigated alloy.

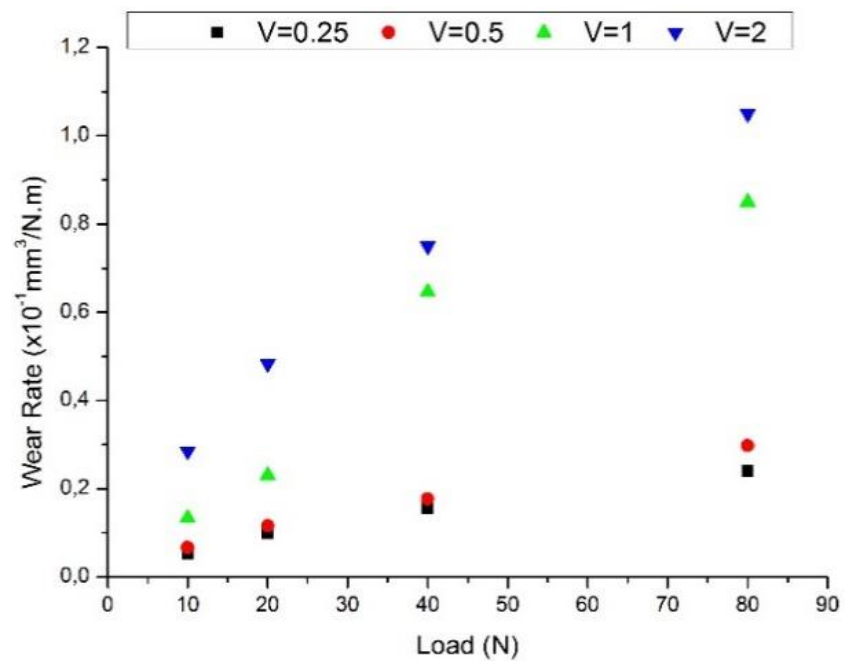

Fig. 2 Effect of applied load on the wear rate of as-cast AZ31B magnesium alloy at different sliding velocities

The effect of sliding velocity on the volumetric wear rates at a constant applied load of 10, 20, 40 and $80 \mathrm{~N}$ for as-cast alloy is presented in Fig. 3. The wear rate increases with enhancing sliding velocity at entire applied loads. A great difference in slope of wear rates occurred at $0.5 \mathrm{~m} / \mathrm{s}$ for as-cast alloy; thus, these indicate that mild wear regime is kept up to $0.5 \mathrm{~m} / \mathrm{s}$ for the same alloy. The results are in broad agreement with the previous investigations [4, $15,16]$, which reported that wear rates increased with an increase in the applied load and sliding velocity. 


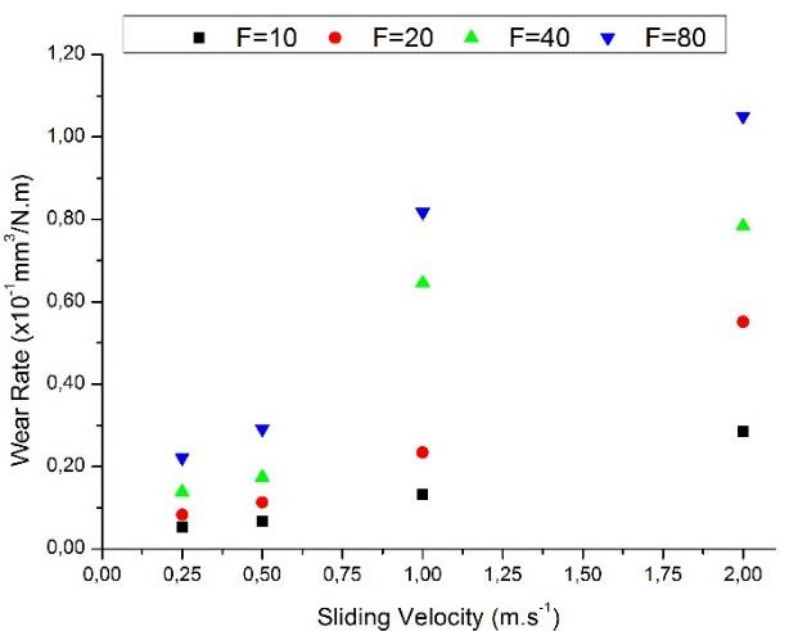

Fig. 3 Effect of sliding velocity on the wear rate of as-cast AZ31B magnesium alloy at different loads

\subsection{Wear mechanisms}

The worn surfaces of the tested pins were observed by SEM and EDS to identify the main wear mechanisms that took place in the different wear conditions for this study. In most of the wear tested conditions, several wear mechanisms occurred, but a definition of the dominant wear mechanism for each wear test was developed. The main wear mechanisms were observed as abrasion, oxidation, delamination, plastic deformation, and melting.

\subsubsection{Abrasion}

Fig. 4 exhibits surface morphology of AZ31B magnesium alloy after dry sliding wear tests. Abrasion wear took place in the as-cast worn surfaces at $10 \mathrm{~N}$ and $0.25 \mathrm{~m} / \mathrm{s}$. In the wear surface, the presence of numerous grooves aligned, mostly parallel to the sliding direction, is evident of abrasion on all the worn pins. This wear mechanism dominates in the medium regimes of load and speed, but it is also available in nearly all the conditions tested mixed with other wear mechanisms. This result is in broad agreement with the previous studies $[4,15,23]$.

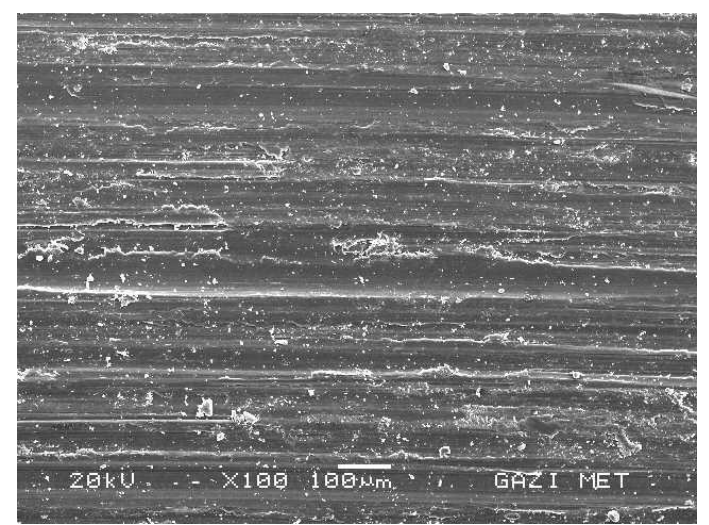

Fig. 4 SEM images of grooves and scratches on the as-cast pin surfaces, showing abrasion at $10 \mathrm{~N}$ and $0.25 \mathrm{~m} / \mathrm{s}$

\subsubsection{Oxidation}

Magnesium alloys are known to have strong tendency to oxidation, so the oxidation of the worn surface plays a significant role in the wear behavior. To determine the rate of oxidation on the different testing conditions, the amount of oxygen on the surface of the samples was evaluated using EDS method. In all the test samples, there was proof of oxidation, but the maximum oxygen peaks were obtained at the middle loads and sliding velocities. In the present study, oxidation wear occurred in the as-cast worn surfaces at $20 \mathrm{~N}$ and $0.5 \mathrm{~m} / \mathrm{s}$ (Fig. 5).

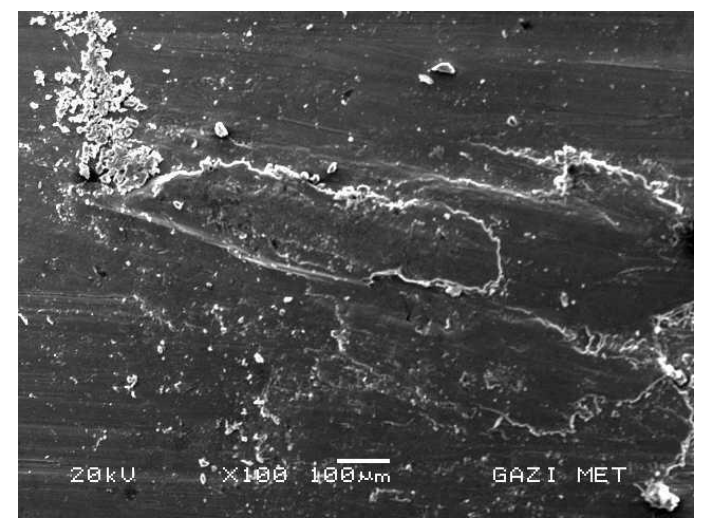

Fig. 5 SEM micrographs showing oxidation of the as-cast alloy pin surfaces, indicating oxidation wear at $20 \mathrm{~N}$ and $0.5 \mathrm{~m} / \mathrm{s}$
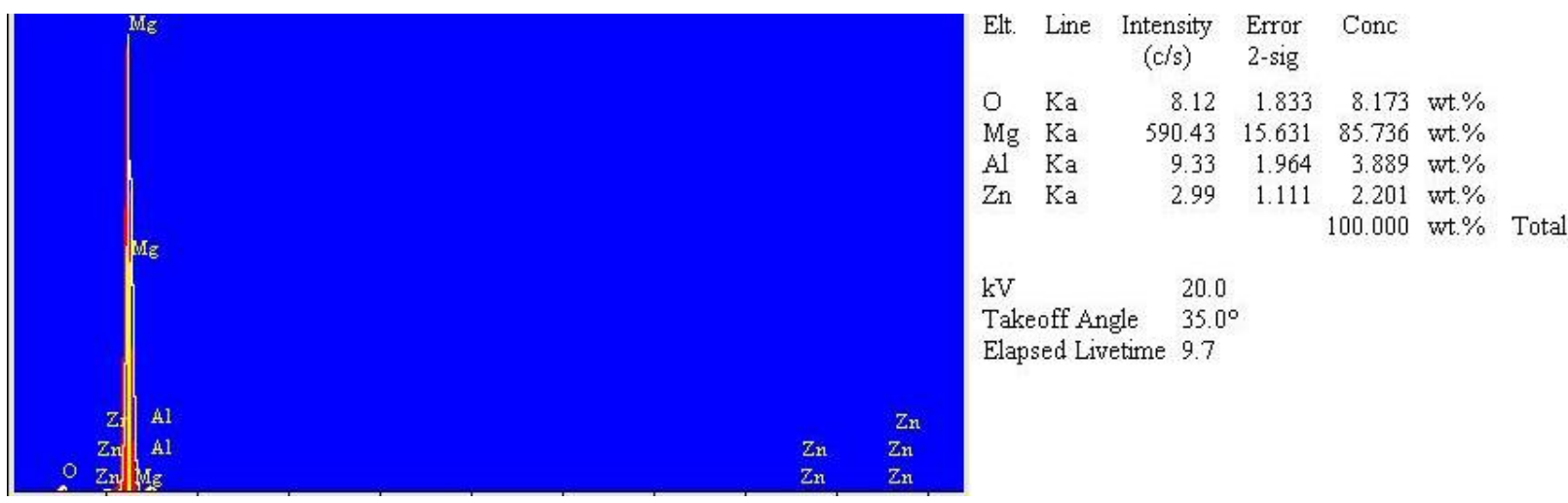

$\mathrm{kV}$

20.0

Takeoff Angle $\quad 35.0^{\circ}$

Elapsed Livetime 9.7

Fig. 6 EDS analysis exhibiting strong oxygen peaks, exhibiting oxidation of worn surfaces of as-cast alloy at $20 \mathrm{~N}$ and $0.5 \mathrm{~m} / \mathrm{s}$

The SEM images clearly show that the dark surfaces are found to be covered broadly by a thin layer of fine particles. The EDS analysis indicated the presence of a strong oxygen peak in the debris in addition to the magnesium peak (Fig. 6). This wear mechanism is referred as the 
oxidative wear [24], in which frictional heating during sliding leads to oxidation of the surface, with wear occurring through the removal of oxide fragments. Due to repeated sliding, oxide wear debris fills out the valleys on the pin surface, and becomes compacted into a protective layer. Thus, metallic contact between disc and pin is prevented and minimum absolute wear rates are measured. Moreover, when the sliding velocity increases, the frictional heating enhances that promotes the formation of a mixture of surface oxides. It is evident that surface oxides show higher hardness than substrate, so it is expected that it makes the wear behavior stable. Selvan et al. [15] reported that the thick oxide layer effectively protected the sliding surface resulting in a mild wear condition with accompanying low wear rate.

\subsubsection{Delamination}

Delamination is a wear mechanism characterized by the detachment of material due to formation of cracks perpendicular to the sliding direction during the wear process. Most of the magnesium alloys have low cold ductility, so there is a significant hardening of the worn surface even using lower loads [4].

Fig. 7 shows the SEM image of delamination wear for as-cast samples at $20 \mathrm{~N}$ and $1 \mathrm{~m} / \mathrm{s}$. When the applied load increases in the mild wear regime, a systematic transition in the wear behavior of the alloy occurs from an oxidational wear to a delamination wear [13]. The existence of an oxygen peak of low intensity in the EDS spectrum of Fig. 8 indicated that the surface was slightly oxidized when the new produced surfaces of the detached particles became in con- tact with the air. In the delamination wear, short cracks occur coarsely perpendicular to the sliding direction. The intersection of these cracks results in the detachment of sheetlike wear particles and the size of crack voids was among $30-75 \mu \mathrm{m}$ in length and $20-40 \mu \mathrm{m}$ in depth. In the delamination wear, the subsurface cracks, which may either exist earlier or get nucleated due to the stresses, propagate during the course of wear. When such subsurface cracks combine the wear surface, delamination is the main wear mechanism [25]. These findings are in broad agreement with similar kind of observations made by earlier researchers $[4,16,26]$.

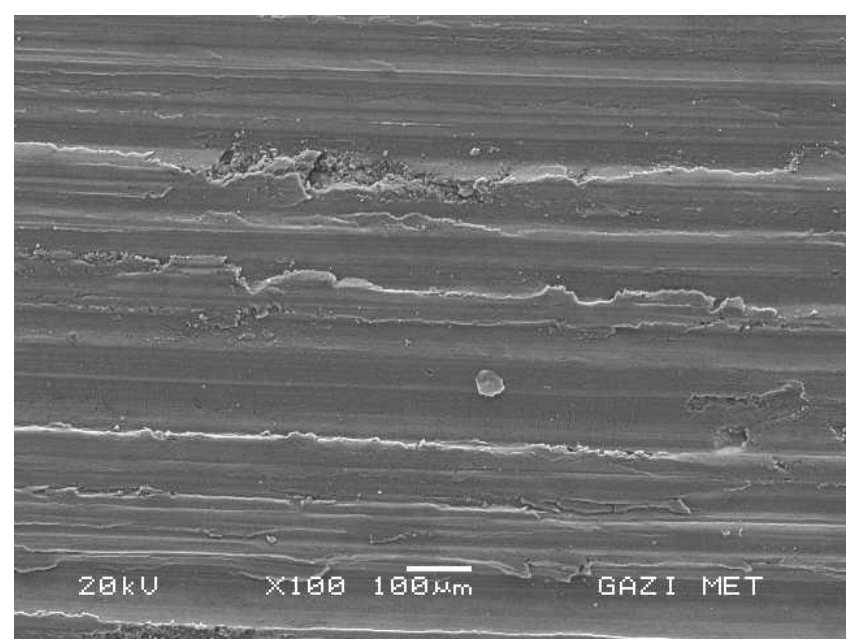

Fig. 7 SEM micrographs showing cracks of the as-cast alloy pin surfaces, indicating delamination at $20 \mathrm{~N}$ and 0.5 $\mathrm{m} / \mathrm{s}$

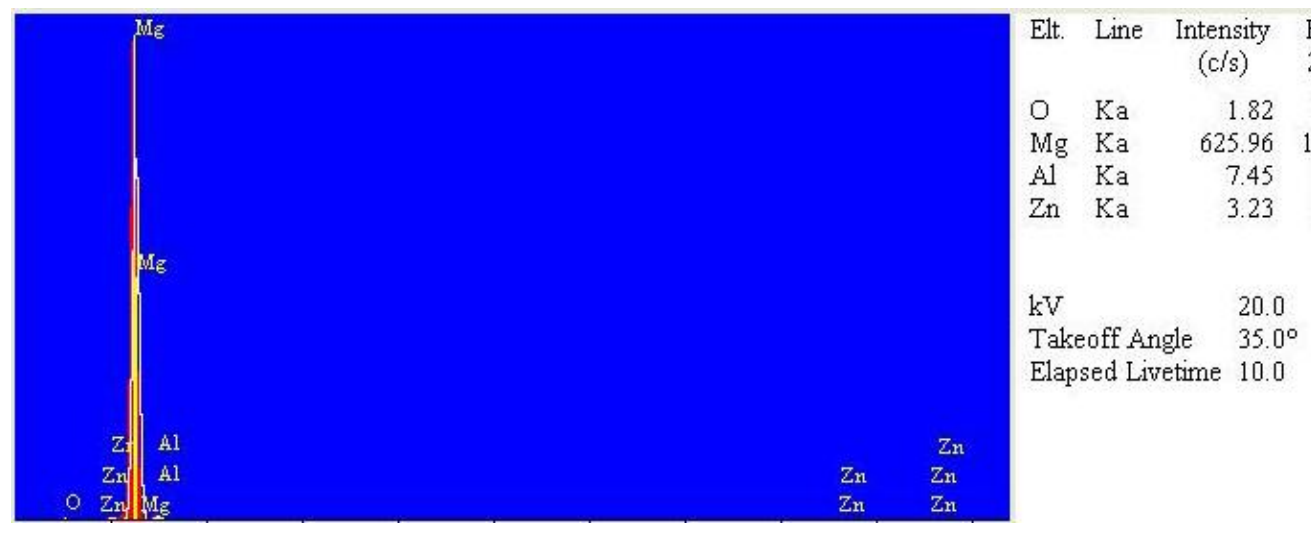

Fig. 8 EDS analysis of as-cast alloy exhibiting low intensity oxygen peaks, indicating delamination with oxide of worn surfaces at $20 \mathrm{~N}$ and $0.5 \mathrm{~m} / \mathrm{s}$

\subsubsection{Plastic deformation}

Plastic deformation is a serious wear mechanism characterized by large surface deformation on the worn surface without cracks. This wear mechanism introduces extensive surface damage; thus, it leads to a higher wear rate with the increase in load and speed. Fig. 9 shows the SEM image of plastic deformation for as-cast samples at $40 \mathrm{~N}$ and 1.0 $\mathrm{m} / \mathrm{s}$. Venkataraman and Sundararajan [27] suggested that the transition from delamination to plastic deformation happened when higher loads and speeds were the issue. They reported that an increase in applied load and sliding velocity resulted in a rise in plastic deformation, which caused a high level of structural corruption and large damage to the surface. The deformed surface layers extended along the sliding direction and out of the contact surface of the sample. It is known that the temperature at the contact surface between steel counterface and test specimen during heavy conditions could reach higher temperatures. The transition between mild to severe wear was accompanied by an important enhancement in the roughness of worn surface of the samples [28]. The increase in the applied load and sliding velocity resulted in a rise in plastic deformation, which caused high level of structural disruption and extensive damage to the material. As the temperature increases, the strength of ascast alloy decreases proportionately and gets softened. Consequently, they become prone to easy plastic deformation and spread out of the contact surface in the direction of sliding as well as by moving sideways [29]. 


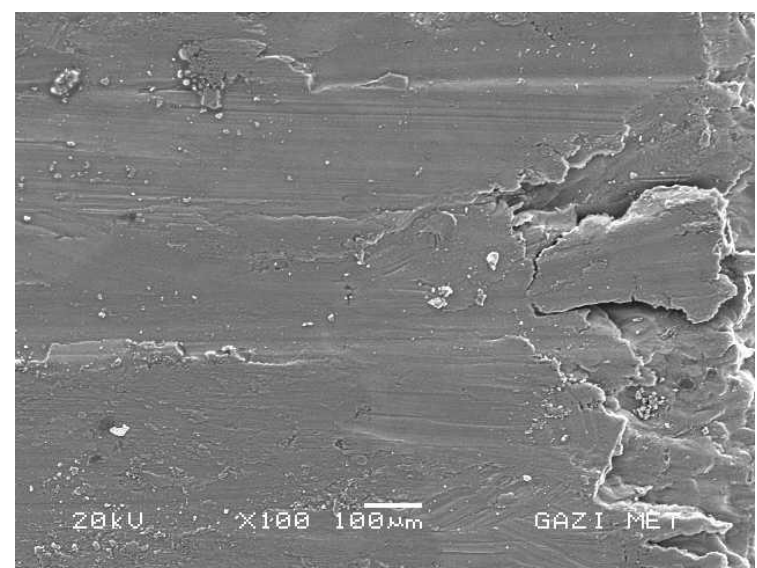

Fig. 9 SEM micrographs showing cracks of the as-cast pin surfaces, indicating plastic deformation at $40 \mathrm{~N}$ and 1 $\mathrm{m} / \mathrm{s}$

\subsubsection{Melting}

Melting in the wear process occurs when the applied load and sliding velocity lead to the highest friction. Fig. 10 exhibits the SEM images of the surface melting on the worn surface of as-cast samples tested at $80 \mathrm{~N}$ and 2.0 $\mathrm{m} / \mathrm{s}$. As the applied load and sliding speed reach crucial threshold limit value, the instant temperatures at the contacting surfaces could exceed the melting point of the alloy, and hence enhancing pin temperature and leading regular softening of both as-cast and hot rolled alloy. A maintained sliding or increase at the applied load and speed will maximize the temperatures, causing melting and a fast increase in the wear rate [30].

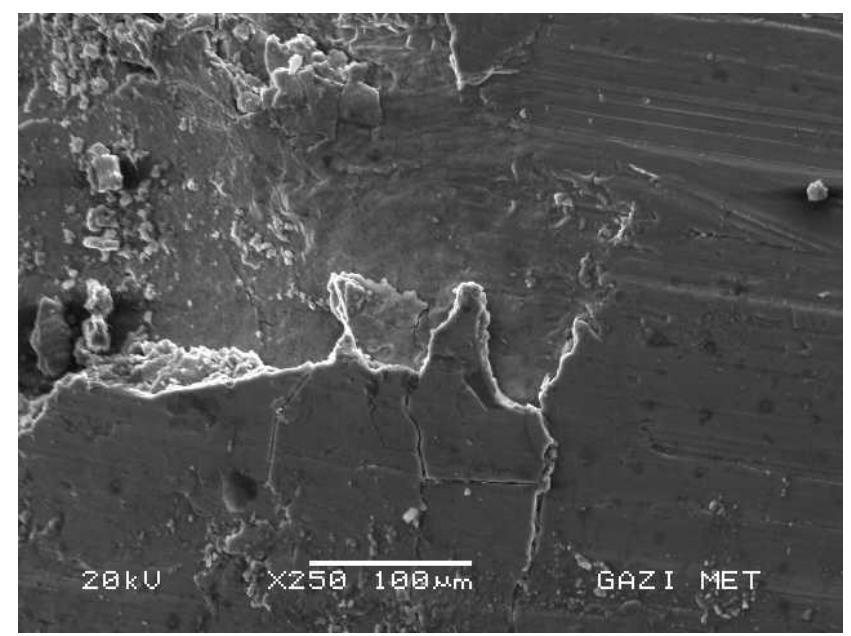

Fig. 10 SEM micrographs showing cracks of the as-cast pin surfaces, indicating melting at $80 \mathrm{~N}$ and $2 \mathrm{~m} / \mathrm{s}$

According to a report published by Huang [31], during the wear tests at the highest applied loads, i.e. above $50 \mathrm{~N}$ the local temperature of the contact surfaces, depending on the test temperature, exceeding the melting temperature of the alloy results in friction-induced surface melting. The molten material spread out of the contact surface in the sliding direction as well as by moving sideways. During the sliding wear, the solidified material formed thin layers. The new layers were continuously generated over the previously formed layers.

\subsection{Construction of wear maps}

Wear rate maps are required to completely understand the wear behaviour of the investigated materials over a range of testing conditions. Firstly, the maps are generated and then they allow subsequent analysis in terms of wear mechanism maps and wear transition maps [32]. Fig. 11 shows the wear rate map of as-cast AZ31B magnesium alloy for different dry sliding conditions. These contour wear rate maps were built on sliding velocity versus applied load axis, operating ORIGIN software and wear rate data. The map describes areas where the main wear mechanism are dominated, though the wear rates change in each region. Each colored zone shows the wear rate for different sliding velocity and applied load conditions. The zones are separated by transition lines, depending on test parameters. The wear rate data are in $m m 3 / m \times 10-1$. The wear rate is maximum at higher applied load and sliding velocity conditions, whereas it is minimum at lower applied load and sliding velocity conditions for the studied alloy.

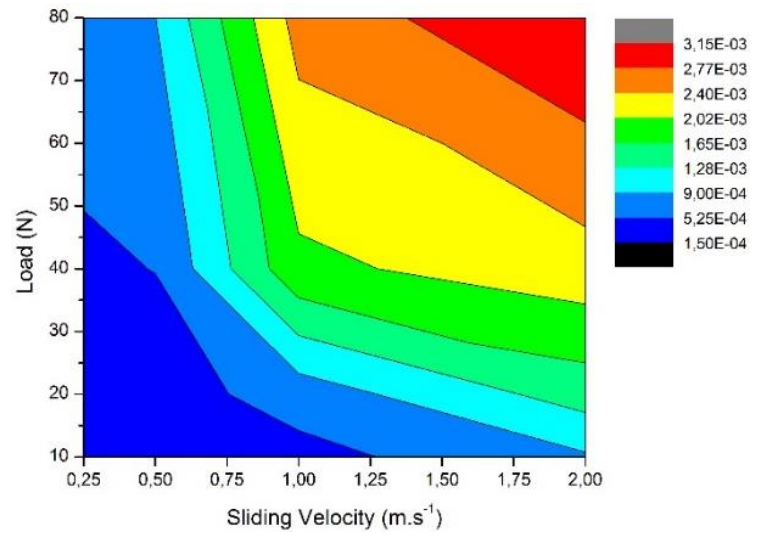

Fig. 11 Wear rate maps of as-cast AZ31B magnesium alloy

Wear mechanisms are characterized by considering complicated changes during the wear. The wear mechanism maps are useful to describe the behavior of the same material. These maps are separated into regions by a transition line which is a function of two or more process parameters. As the contour maps are analyzed, lines of equal spacing and lack of curvature usually mean the same dominant mechanism. The recesses and ledges on the map generally recommend some change in the wear type. Hence, regions with potentially different wear mechanism can be defined.

Wear mechanism maps can also help, like a guideline, to select wear resistant materials and suitable counterfaces for them. Zhang and Alpas [28] recommended that wear mechanism maps could be a helpful instrument to forecast the wear conditions. Fig. 12 exhibits the wear mechanism map for as-cast AZ31B magnesium alloy.

Wear transitions could be described as the rapid increase in the wear rate over a small change in such conditions as load, speed, temperature, or time. Wear transition plots provide an opportunity to examine the different wear mechanisms in each region for the investigated materials under various wear parameters. Three wear regimes are obtained as mild wear, severe wear, and ultra-severe wear for as-cast alloys. In the mild wear regime, the wear takes place by abrasion, oxidation and delamination of the bulk material. These wear mechanisms are dominant in the mild wear regime. For industrial applications, the mild wear regime 
could be considered as "acceptable" operation regime because the wear rates are typically low and wear proceeds under steady-state condition [33]. Plastic deformation-based wear is the dominant wear mechanism in the severe wear regime. An increase in sliding velocity and the applied load leading to a rise in the local temperature at contact surfaces of the alloy brings about great plastic deformation. The transition from mild to severe wear is checked by sliding velocity and applied load. Surface melting is the dominant wear mechanism in the ultra-severe wear regime. A further increase in sliding velocity and the applied load lead to higher contact temperatures between specimen and steel disc and an increase in the frictional heat which causes surface melting. In addition, the transition from severe wear to ultra-severe wear is checked by sliding velocity and applied load.

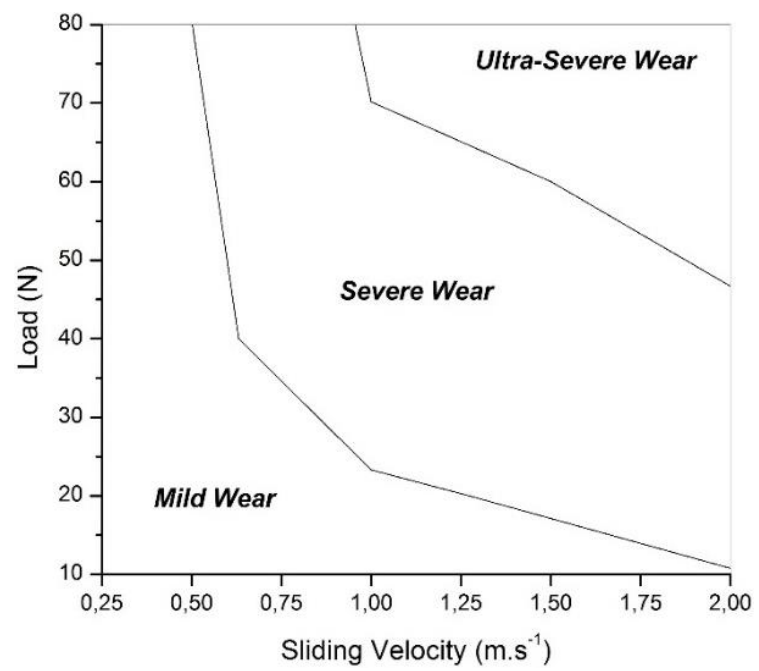

Fig. 12 Wear mechanism map of as-cast AZ31B magnesium alloy

\section{Conclusions}

In the current study, the wear behavior of as-cast AZ31B magnesium alloy has been studied in a range of applied load from 10 to $80 \mathrm{~N}$ combined with different sliding speeds, i.e. $0.25,0.5,1$ and $2 \mathrm{~m} . \mathrm{s}-1$ and a constant sliding distance of $2500 \mathrm{~m}$. Wear maps such as wear rate and wear mechanism have been constructed by using the calculated wear parameters and SEM analysis of the worn surface. As a result, the following conclusions can be drawn:

1. The wear rate goes up with the increase in sliding velocity and the applied load for AZ31B magnesium alloy.

2. The main wear mechanisms observed were as abrasion, oxidation, delamination, plastic deformation, and melting.

3. Wear surfaces unveiled that the sliding wear behavior of as-cast AZ31B magnesium alloy can be classified into three wear regimes, named as mild wear, severe wear, and ultra-severe wear as characterized by SEM.

4. The dominant wear mechanisms in each regime were identified and summarized in the wear mechanism map.

5. Abrasion, delamination and oxidation wear are predominant wear mechanisms in the mild wear regime, while plastic deformation wear is the dominant wear mechanism in the severe wear regime.

6. Melting wear is the dominant wear mechanism in the ultra-severe wear regime.
7. The wear rate of the as-cast AZ31B magnesium alloy depends on the applied load and sliding velocity.

\section{Acknowledgements}

The author would wish to thank Magnum Engineering R\&D Company Ankara-TURKEY for providing material and technical assistance. The invaluable contribution of Dr. Onur Çavuşoğlu, in making the wear test is gratefully acknowledged.

\section{References}

1. Bhowmick, S.; Lukitsch, M.J.; Alpas, A.T. 2010. Dry and minimum quantity lubrication drilling of cast magnesium alloy, Int. J. Mach. Tool Manu. 50, 444-457. https://doi.org/10.1016/j.ijmachtools.2010.02.001.

2. Kainer, K.U. 2003. Magnesium Alloys and Technology. Wiley-VCH Verlag GmbH\&Co. KGaA, Weinheim $1-23$.

3. Avedesian, M.M.; Baker, H. 1999. Magnesium and Magnesium Alloys (ASM Specialty Handbook), ASM international, New York.

4. Taltavull, C.; Rodrigo, P.; Torres, B.; Lopez, A.J.; Rams, J. 2014. Dry sliding wear behavior of AM50B magnesium alloy, Mater. Design 56, 549-556. http://dx.doi.org/10.1016/j.matdes.2013.12.015.

5. Wang, S.Q.; Yang, Z.R.; Zhao, Y.T.; Wei, M.X. 2010. Sliding wear characteristics of AZ91D alloy at ambient temperatures of $25-200^{\circ} \mathrm{C}$, Tribol. Lett. 39, 39-45. https://doi.org/10.1007/s11249-009-9569-5.

6. Luo, A.A. 2004. Recent magnesium alloy development for elevated temperature applications, Int. Mater. Rev. 49, 13-30. http://dx.doi.org/10.1179/095066004225010497.

7. Shanthi, M; Lim, C.Y.H.; Lu, L. 2007. Effects of grain size on the wear of recycled AZ91 Mg, Tribol. Int. 40, 335-338. http://dx.doi.org/10.1016/j.triboint.2005.11.025.

8. Xu, C.; Furukawa, M.; Horita, Z.; Langdon, T.G. 2004. Severe plastic deformation as a processing tool for developing superplastic metals, J. Alloys Compd. 378, 27-34. http://dx.doi.org/10.1016/j.jallcom.2003.10.065.

9. Mehta, D.S.; Masoodand, S.H.; Song, W.Q. 2004. Investigation of wear properties of magnesium and aluminum alloys for automotive applications, J. Mater. Process. Technol. 155-156, 1526-1531. http://dx.doi.org/10.1016/j.matprotech.2004.247.

10. Huang, W.; Hou, B.; Pang, Zhou, Y.Z. 2006. Fretting wear behavior of AZ91D and AM60B magnesium alloys, Wear. 260, 1173-1178. http://dx.doi.org/10.1016/j.wear.2005.07.023.

11. Blau, P.J.; Walukas, M. 2000. Sliding friction and wear of magnesium alloy AZ91D produced by two different methods, Tribol. Int. 33, 573-579. http://dx.doi.org/ 10.1016/S0301-679X(00)00108-0.

12. Chen, H.; Alpas, A.T. 2000. Sliding wear map for the magnesium alloy Mg-9Al-0.9Zn (AZ91), Wear 246, 106-116. http://dx.doi.org/10.1016/S0043-1648(00)00495-6.

13. An, J.; Li, R.G.; Lu, Y.; Chen, C.M.; Xu, Y.; Chen, X.; Wang, L.M. 2008. Dry sliding wear behavior of magnesium alloys, Wear 265, 97-104. 
http://dx.doi.org/ 10.1016/j.wear.2007.08.021.

14. Chen, T.J.; Ma, Y.; Li, B.; Li, Y.D.; Hao, Y. 2007. Wear behavior of thixoformed AZ91D magnesium alloy: A comparison with permanent mould cast alloy, Mater. Sci. Eng. A. 445, 477-485. http://dx.doi.org/10.1016/j.msea.2006.09.112.

15. Selvan, S.A.; Ramanathan, S. 2010. Dry sliding wear behavior of as-cast ZE41A magnesium alloy, Mater. Design 31, 1930-1936. http://dx.doi.org/ 10.1016/j.matdes.2009.10.054.

16. Lopez, A.J.; Rodrigo, P.; Torres, B.; Rams, J. 2011. Dry sliding wear behavior of ZE41A magnesium alloy, Wear 271, 2836- 2844. http://dx.doi.org/ 10.1016/j.wear.2011.05.043.

17. Taltavull, C.; Torres, B.; Lopez, A.J.; Rams, J. 2013. Dry sliding wear behavior of AM60B magnesium alloy, Wear 301, 615-625. http://dx.doi.org/ 10.1016/j.wear.2012.11.039.

18. Habibnejad-Korayem, M.; Mahmudi, R.; Ghasemi, H.M.; Poole, W.J. 2010. Tribological behavior of pure $\mathrm{Mg}$ and $\mathrm{AZ3} 1$ magnesium alloy strengthened by $\mathrm{Al}_{2} \mathrm{O}_{3}$ nano-particles, Wear 268, 405-412. http://dx.doi.org/ 10.1016/j.wear.2009.08.031.

19. Ding, W.; Jiang, H.; Zeng, X.; Li, D.; Yao, S. 2007. Microstructure and mechanical properties of GTA surface modified composite layer on magnesium alloy AZ31 with SiCp, J. Alloys Compd. 429, 233-241. http://dx.doi.org/ 10.1016/j.jallcom.2006.03.083.

20. Standard test method for wear testing with a pin-on-disk apparatus. 2000. ASTM G99 95a,

21. Archard, J.F. 1953. Contact and Rubbing of Flat Surfaces, J. Appl. Phys. 24, 981-988. https://doi.org/10.1063/1.1721448.

22. ISO6507-1 Metallic materials-Vickers hardness test Part 1: Test method ISO 2005.

23. Lin, Z.; Xuan-hui, Q.; Bo-hua, D.; Xin-bo, H.; Mingli, Q. 2008. Effect of porosity on wear resistance of $\mathrm{SiC} / \mathrm{Cu}$ composites prepared by pressureless infiltration, Trans. Nonferrous Met. Soc. China. 18, 1076-1082. http://dx.doi.org/ 10.1016/S1003-6326(08)60184-3.

24. Aung, N.N.; Zhou, W.; Lim, L.E.N. 2008. Wear behaviour of AZ91D alloy at low sliding speeds, Wear. 265, 780-786.

http://dx.doi.org/ 10.1016/j.wear.2008.01.012.

25. Zafari, A.; Ghasemi, H.M.; Mahmudi, R. 2012. Tribological behavior of AZ91D magnesium alloy at elevated temperatures, Wear 292-293, 33-40. http://dx.doi.org/ 10.1016/j.wear.2012.06.002.

26. Lim, S.C. 2002. The relevance of wear-mechanism maps to mild-oxidational wear, Tribol. Int. 35, 717-23. http://dx.doi.org/ 10.1016/S0301-679X(02)00033-6.

27. Venkataraman, B.; Sundararajan, G. 1996. The sliding wear behaviour of Al-SiC particulate composites-I. Macrobehaviour, Acta Mater. 44 451-460. http://dx.doi.org/ 10.1016/1359-6454(95)00217-0

28. Zhang, J.; Alpas A.T. 1997. Transition between mild and severe wear in aluminium alloys, Acta Mater. 45, 513-528. http://dx.doi.org/ 10.1016/S1359-6454(96)00191-7.

29. Mondal, A.K.; Chandra Rao, B.S.S.; Kumar, S. 2007, Wear behaviour of AE42+20\% saffil Mg-MMC. Tribol. Int. 40, 290-296. http://dx.doi.org/ 10.1016/j.triboint.2005.09.016.

30. Lim, C.Y.H., Lim, S.C., Gupta, M. 2003. Wear behaviour of SiCp-reinforced magnesium matrix composites, Wear. 255 629-637. http://dx.doi.org/ 10.1016/S0043-1648(03)00121-2.

31. Wei-jiu, H.; Qiang, L.; Cheng-long, L. 2012. Tribological behaviour of AZ71E alloy at high temperatures, Trans. Nonferrous Met. Soc. China. 22, 2057-2065. http://dx.doi.org/ 10.1016/S1003-6326(11)61428-3.

32. Hsu, S.M.; Shan, M.C. 1996. Ceramic wear maps, Wear. 200, 154-75 (1-2) http://dx.doi.org/ 10.1016/S0043-1648(96)07326-7.

33. Selvan, S.A.; Ramanathan, S. 2010. A comparative study of the wear behavior of as-cast and hot extruded ZE41A magnesium alloy, J. Alloys Compd. 502, 459502. http://dx.doi.org/ 10.1016/j.jallcom.2010.04.205.

\section{Faruk Mert}

\section{DRY SLIDING WEAR BEHAVIOUR OF AS-CAST AZ31B MAGNESIUM ALLOY}

S u m m a r y

This study investigates dry sliding wear behavior of as-cast AZ31B magnesium alloy using a pin-on-disc type wear apparatus against EN42 steel with heat treatment as counterface. A wear mapping approach has been undertaken to represent the wear regimes and the main mechanism of wear in each regime. Wear resistance of as-cast AZ31B magnesium alloy was tested using pin-on disc method with heat-treated high-carbon steel discs as counterface on drysliding conditions. Wear tests at a fixed sliding distance of $2500 \mathrm{~m}$ were performed in sliding velocities of $0.25,0.5,1$ and $2 \mathrm{~m} / \mathrm{s}$, loads of 10, 20, 40 and $80 \mathrm{~N}$. Microstructural examinations of worn surfaces of pins were characterized using SEM/EDS. Wear mechanism map of investigated material was drawn. The main wear mechanisms in each test conditions were identified and classified using the wear mechanism map. Three wear regimes, namely mild wear, severe wear, and ultra-severe wear were defined, based on the results. Consequently, ultra-severe plastic deformation is the main wear mechanism at the highest applied load and sliding velocity speed.

Keywords: Dry sliding wear, AZ31B magnesium alloy, wear mechanisms, wear map.

Received July 19, 2016

Accepted October 13, 2017 